\title{
Actualising Bergson's lesson: a post-post-modernist perspective
}

\section{Gianluca Colombo}

Published online: 17 January 2009

(C) Springer Science+Business Media, LLC. 2009

Henri Bergson (1859-1941) is one of the most popular French philosophers whose influence has been very strong in the Western society during his life. He was then rather neglected during the fifties and sixties which were dominated by French structuralism and by the Heidegger's phenomenon. In more recent times, his thought was re-discovered, mainly thanks to Deleuze (1991). Bergson thus became one of the cult authors of post-modernism and in this perspective he has been one of the key references in organisation and strategic management literature. His ideas and theories are in fact very original and intriguing; it might therefore be useful to reconsider how Bergson can still contribute to research in management beyond the post-modernist perspective. In one of my last conversations with Roland Calori, about a paper in which he was using Bergson's "duration" and "intuition" and "creative evolution" to analyse the relationships between organisational development and the lay ontology of organisational members (Calori 2002), I discovered that Bergson was important, non-only for the contents of his philosophy, but also for the methodological suggestions one can draw from his books. At that time I was very interested in the complex theories and in the epistemological consequences of complexity in organisations. I found this conversation with Roland particularly enlightening and intense (this was always the case with him!). I was therefore very pleased when Edoardo Mollona asked me to take part in this book review and I immediately decided that I would work on Bergson's influence in management literature. This is not an easy task as many scholars have used Bergson as a source of inspiration and his theories as a reference framework. For the reader of this note I suggest at least three good reasons to read or re-read Bergson. First of all his

\footnotetext{
G. Colombo

Department of Management, University of Lugano, Lugano, Switzerland

G. Colombo $(\bowtie)$

Department of Economics, University of Insubria, Varese, Italy

e-mail: Gianluca.Colombo@uninsubria.it
} 
philosophy is still very relevant and his ideas can be inspirational in many fields including management. Further, it is very well written and translated into delightful pre-war English. Finally, after having reconsidered Bergson, it will be a real pleasure to read (re-read) one of Roland Calori's best papers (Calori 2002).

This note is organised as follows. Section 1 is devoted to a summary of Bergson's philosophy as it emerges from his major writings. Section 2 is a brief analysis of how organisation and strategy scholars received Bergson, after Deleuze's revitalisation in the eighties. Finally in Sect. 3, I discuss whether Bergson's philosophy can still be inspirational for researchers in management science. I will focus here mainly on strategic change and entrepreneurship. My conclusive remarks will address the issue I discussed with Roland: namely the methodological implications of Bergson's lesson.

\section{Bergson - the philosopher of intuition, duration, creativity ... and dynamic religion}

The first entry to Bergson's philosophy is the concept of multiplicity, which has been developed in two ways during the XX century: Bergsonism and phenomenology (Deleuze 1991, pp. 115-118). For Bergson, "the immediate data of consciousness" (les données immédiates de la conscience) are a multiplicity. This concept is clear from the title of the French version (Essai sur les données immédiates de la conscience). The English title of this work is Time and Free Will: An Essay on the Immediate Data of Consciousness (1919). In order to define freedom, which depends on consciousness, Bergson proposes a differentiation between time and space. Consciousness is temporal; it is the duration (la durée). In the duration, there is no juxtaposition of events; therefore there is no mechanistic causality. The absence of such a causality makes the experience of freedom possible. The duration is a qualitative multiplicity and not a quantitative multiplicity; this important distinction explains why there is no negation in the duration. For Bergson freedom is mobility and this, according to Lawlor and Moulard (2008) is probably one of his best insights. In his An Introduction to Metaphysics, Bergson uses the image of an elastic band being stretched. If we contract the band to a mathematical point, we will have a representation of our present experience (the now). Then, if we stretch it to make a line growing progressively longer, this action of tracing a line can represent the duration, which is thus a movement. But, the image of the elastic is still, according to Bergson, incomplete. For him, no image can represent duration. An image is immobile, while duration is "pure mobility" (The Creative Mind, (1992) p. 165). Another key concept in Bergson's philosophy is intuition. The theory of intuition is particularly developed in An Introduction to Metaphysics. Intuition is considered a kind of experience the consequence of a sort of sympathy (The Creative Mind, (1992) p. 159). Intuition then consists in entering into things, rather than approaching them from outside. Moreover intuition is always an intuition of duration. To experience the intuition, we should accomplish a series of acts, which correspond to the method of intuition. 
With Matter and Memory Bergson wants to show that-beyond both realism and idealism-our knowledge of things, in its pure state, takes place within the things it represents. Like intuition, true knowledge is possible only from the inside and requires a sort of sympathy with the known entity. The relationship between the reality of the spirit and the reality of matter is analysed using the example of memory. In fact memory is in a way at the intersection between mind and matter (Matter and Memory, 1991, p. 13). Moreover Bergson's concept of intuition is memory (Lawlor and Moulard 2008). At the end of the introduction of Matter and Memory, Bergson discloses two principles that have inspired his research. "The first is that in psychological analysis we must never forget the utilitarian character of our mental functions, which are essentially turned toward action. The second is that the habits formed in action find their way up to the sphere of speculation, where they create fictitious problems, and that metaphysics must begin by dispersing this artificial obscurity" (Matter and memory, 1991, p.16). This conclusion reveals a great deal about the pragmatic character of Bergson's philosophy and suggests an action research methodology. We will come back to this point in the last section of this note.

Intuition (memory) is creative movement, which leads to Creative Evolution (2005), the book that probably had the greater influence on social scientists. What Bergson attempts with Creative Evolution, is to build a theory that integrates both the continuity of life, as stated in the concepts of duration and memory, and the discontinuity of creation. This integrative approach reveals a understanding of change and its deeper causes. The impulse, which explains all form of creation, is the élan vital. Intelligence, which comprehends the world with an analytical, spacialised and practical approach, structures human knowledge. Thus it cannot reach the essence of life in its duration. Intuition, on the other hand, gets close to the original creative impulse making the true knowledge of duration possible (continuity and discontinuity). What is interesting from a theory of knowledge point of view is that through intuition we can turn intelligence against itself. On this basis we can propose a critique to the concept of tacit knowledge (Styhre 2004). A quid of intuition is silent but yet alive within the intellect-based knowledge and it can be awaked when certain conditions occur. The role of the philosopher and probably also the role of the entrepreneur (intrapreneur) is to allow this intuition to emerge, to nurture it, then to expand it; and this process coincides with the spirit and with life.

Bergson himself considers, The Two Sources of Morality and Religion (1977), his final book, as a development of Creative Evolution. There is in fact a mixture of two kinds of morality: the closed morality, which corresponds to a static religion, and the open morality (dynamic religion). Closed morality and static religion promote social cohesion and are instrumental for the survival of a given society, excluding other societies and often leading to conflicts between societies. Open morality and dynamic religion promote creativity and progress. They are "open" because they include everyone, leading to universal peace. This book presents a grandiose utopia, which emerges clearly in the final remarks (Hatzenberger 2003). Interestingly, the methods and structure of the book are quite close to Creative Evolution, suggesting that on the one hand the method of intuition can lead to both to creativity and to 
open morality; on the other hand open morality and dynamic religion are the only context where creativity and intuition (thus duration and true life) are possible. In fact, what Bergson calls the impetus of love (The Two Sources, p. 96), is a mixture of joy and sympathy; it is a kind of creative emotion, needed to reach true intuition and knowledge.

\section{Bergson's cult in the post-modernist literature}

As mentioned earlier, Deleuze was instrumental in re-launching Bergson's ideas. The concept of multiplicity and the theory of duration was acquired by postmodernist philosophers and transferred to post-modernist driven social scientists, management scholars included by Deleuze. In their introduction to a special issue of Culture and Organization, Linstead and Mullarkey (2003) posit that the interest of social scientists for Bergson has to be based in his theory of time and in the related philosophy of creativity, invention and intuition. In fact, both creativity and time are "neglected dimensions of culture and organizational culture in particular" (Linstead and Mullarkey 2003: 3). In the same vein, Isaack (1978) suggests that management scholars have overlooked intuition, while it should be at the core of many areas of research. He also suggests that the differentiation (and the tension) between intuition and intellect, also supported by the findings about the brain 's organisation (Isaack 1978: 919), should lead to new reflections on organisational change and innovation, offering at the same time insights for management education. Time multiplicity becomes a key concept to reinterpret the knowledge-based view (KBV) of the firm and in particular how knowledge can be integrated across and within organisations (Reinmoeller and Chong 2002). One key dimension in the KBV is tacit knowledge (Polanyi 1958; Nonaka and Takeushi 1995). But as Styhre points out, Bergson considers that knowledge cannot be split into explicit and tacit. We can differentiate between the two faculties of cognition: intellect and intuition, which complement each other in the knowledge process. Understanding the difference and the relationships between these two faculties is more important than differentiating between the two knowledge components, which cannot be seen as discrete categories (Styhre 2004:185). The virtual dimension of Knowledge is, according to Styhre (2003) another consequence of the philosophy of duration and its revitalisation by Deleuze (1991). A practical feeling of this dimension can be found in Proust' s Remembrance of the Time Past. For him "the past and the present are always entangled while the present dwells in the shadows of the future" (Styhre 2003: 18). As Proust said: virtual is real without being actual and ideal without being abstract. And knowledge is virtual because always in a state of becoming; this is why knowing is probably more interesting for researchers than knowledge. And Knowing is "never here and now, but always already bounded by the past and the future" (Styhre 2003: 19). On the basis of this theory, management scholars should shift their interest from knowledge to knowing. This would probably mean avoiding a definition of knowledge as stock, while in Bergson's view it is always a process and it evolves continuously when put into practice. Adopting a Bergsonean perspective, actionable knowledge can only be virtual knowledge. 
Post-modern approaches are often considered appropriate to complex systems (theories). For instance the key concept of emergence and process philosophy are key references to frame complexity (Letiche 2000). Based on Bergson's concepts of duration, intuition and élan vital, the author proposes to reconsider organisational change (and self-organisation) in a true process-based perspective, where, for example "circumstance interpretation and activity intermix" (Letiche 2000: 554) and where emergence becomes at the same time the focus and the tool for an action (experience)-oriented research.

\section{How Bergson can inspire the research in entrepreneurship and organisational change}

In order to understand Bergson's lesson related to management science and practice, I propose a review of Calori's paper on Organizational Development and the Ontology of Creative Dialectical Evolution (Calori 2002). In this paper, Organisational Development is approached "looking at the ontology which guides the behaviour of organisational members rather than the epistemology features of knowledge creation" (Calori 2002: 128), as in the KBV of the firm. Moreover, once we focus our attention to the "lay ontology" of organisational members, we begin to view their ontological principles as a part of a practice-oriented theory and their authors (actors) as practice-oriented theorists. How does Bergson enter into this picture? Simply because, according to Calori "executives who see being and reality as a continuous movement, a creative dialectical evolution can stimulate the development of their organization" (Calori 2002: 129). The dialectical evolution proposed by Bergson is similar to hyperdialectics (Merleau-Ponty 1968). And in fact Maurice Merleau-Ponty at the end of his life contributed to Bergson's revitalisation, acknowledging his debt toward Bergson's theory of creative evolution. The practical implication of adopting Bergson's theory, when we approach organisational change, is that processes are seen as driven by intuition and impetus, more than as planned or designed. The framework based on Bergson's principles combines two moments of the dialectical evolution: becoming and relating. In both moment hyperdialectics is represented by tensions, between the actual identity and the desired future, between the awareness of the past and the new actions, between single-global identities and multiple-local identities, between the desire to transfer and integrate and the desire to differentiate and diversify (Calori 2002: 144-145). This framework is clearly grounded in Bergson's Creative Evolution (2005), but also in Matter and Memory (1991) and The Two Sources of Morality and Religion (1977). In particular, we may look at open morality and dynamic religion as a source of inspiration to identify the conditions of organisational development.

Bergson's notions of duration, impetus (élan vital) and the theory of creative evolution can also inspire research in entrepreneurship in many ways. In particular the discovery process can be enlightened by the ontology of creative evolution and Calori's framework can be revisited and applied to the entrepreneurial (intrapreneurial process). The impetus can be view as a typical characteristic of 
entrepreneurs and intrapreneurs who are able to innovate because they stay in the duration, which means that they are part of the processes emerging within the organisation and within the environment. For instance, planning according to the pace of the new business (MacMillan and Low 1986) is an example that habitual entrepreneurs show superior abilities to place themselves in the duration of the entrepreneurial process.

\section{Conclusive remarks: Bergson's lesson and its methodological implications}

I have attempted to illustrate how Bergson's philosophy can offer ideas, notions and theories that are still useful in management research. After a brief résumé of his major books, I have analysed how some scholars, who broadly belong to postmodernism, received Bergson, after Deleuze reconsidered his contribution. I finally focus on Calori (2002) where Bergson is used to renew the approach to organisational development. Similarly, I suggest that Bergson's philosophy could inspire research on entrepreneurial processes. In my conclusive remarks, I would like to underline two methodological implications. The first one is based on the notion of intuition as a method. According to Bergson, true knowledge is intuition and intuition is memory; intuition implies sympathy with its object. Moreover, intuition is knowledge from inside. In epistemological terms, this means interpenetration between knower and known or, more radically, between two "knowings". In this perspective, dialectical creative evolution both in research and in management practice can be implemented through participatory action-research. The other methodological suggestion refers to modelling in research. Bergson's intuition is a pre-verbal ability. In fact Bergson considered linguistic abilities functional to intellect more than to intuition. In management, modelling is often like building a language that connects different times and durations. A case of time multiplicity is that researchers and managers live in different durations. Through modelling, we initiate a dialogue, which may help to co-ordinate between different times and simultaneous occurrences. The risk is that we may be trapped by the model, which might freeze the process, a snapshot in Bergson's terms. The conclusion may be that we need modelling to coordinate researchers and organisational actors' durations, but we also need to overcome our models in order to keep researchers and organisational actors within pure duration. Open and dynamic modelling in research could have the same function that open morality and dynamic religion have in society.

\section{References}

Bergson, H. (1919). Time and free will: An essay on the immediate data of consciousness. New York: Macmillan. (translation of Essai sur le données immédiates de la conscience: Paris, 1889).

Bergson, H. (1977). The two sources of morality and religion. Notre Dame, Indiana: University of Notre Dame Press. (1st French edition: Paris, 1932; 1st English translation: London 1935). 
Bergson, H. (1991). Matter and memory. New York: Zone books. (1st French edition: Paris, 1896; 1st English translation: New York 1911).

Bergson, H. (1992). The creative mind. New York: The Citadel Press [1946] (Skiza, A. (Ed.). translation of La Pensée et le mouvant, Paris, 1946).

Bergson, H. (2005). Creative evolution. New York: Cosmo Classics. (1st French Edition: Paris, 1907; 1st English translation: New York 1911).

Calori, R. (2002). Organizational development and the ontology of creative dialectical evolution. Organization, 9(1), 127-150.

Deleuze, G. (1991). Bergsonism. New York: Zone Books.

Hatzenberger, A. (2003). Open society and bolos: A Utopian reading of Bergson's 'Final Remarks'. Culture and Organization, 9(1), 43-58.

Isaack, Th. S. (1978). Intuition: An ignored dimension of management. Academy of Management Review, 3(4), 917-922.

Lawlor, L., \& Moulard, V. (2008). Henri Bergson. Metaphysics Research Lab, CSLI, Stanford: Stanford University.

Letiche, H. (2000). Phenomenal complexity theory as informed by Bergson. Journal of Organizational Change Management, 13(6), 545-557.

Linstead, S., \& Mullarkey, J. (2003). Time, creativity and culture: Introducing Bergson. Culture and Organization, 9(1), 3-13.

MacMillan, I. C., \& Low, M. B. (1986). Techniques of the "Habitual" entrepreneur: Flow building and progress optimization, Working Paper of the Snider Entrepreneurial Centre The Wharton School, October.

Merleau-Ponty, M. (1968). The visible and the invisible. Evanston, IL: Northwestern University Press.

Nonaka, I., \& Takeushi, H. (1995). The knowledge-creating company. Oxford: Oxford University Press.

Polanyi, M. (1958). Personal knowledge: toward a post-critical philosophy. Chicago: Chicago University Press.

Reinmoeller, P., \& Chong, L.-C. (2002). Managing the knowledge-creating context: A strategic time approach. Creativity and Innovation Management, 11(3), 165-174.

Styhre, A. (2003). Knowledge as a virtual asset: Bergson's notion of virtuality and organisational knowledge. Culture and Organization, 9(1), 15-26.

Styhre, A. (2004). Rethinking knowledge: A Bergsonean critique of the notion of tacit knowledge. British Journal of Management, 15, 177-188.

\section{Author Biography}

Gianluca Colombo is full professor of Management at the University of Lugano and at the University of Insubria (Varese). He is the Head of the Department of Management at the University of Lugano. He is distinguished professor of strategy at SDA-Bocconi. He is member of the SMS (Strategic Management Society), the AIMS (Association Internationale de Management Stratégique), the SDS (System Dynamics Society) and the EURAM. His fields of research are: Merger \& Acquisitions, Family Business, System thinking and complexity in management. 